\title{
HEAT EFFICIENCY OF MULTI-STAGE ZEOLITE SYSTEMS FOR LOW TEMPERATURE DRYING
}

\author{
M. Djaeni, G. van Straten, A.J.B. van Boxtel \\ Systems And Control Group, Wageningen University, PO Box 17, 6700 AA Wageningen \\ The Netherlands, email:mohamad.djaeni@wur.nl \\ P.V. BARTELS, J.P.M. SANDERS \\ Agrotechnology And Food Science Group, Wageningen University, PO Box 17, 6700 AA \\ Wageningen The Netherlands,
}

\begin{abstract}
This work presents the evaluation of multi-stage adsorption dryers with air dehumidification by zeolite and alumina pillared clay. In a multi-stage dryer product is dried in a number of succeeding stages and for each stage the air is dehumidified by the adsorbent. The exhaust air from each stage is reused for product drying in a following stage after passing a bed with adsorbent. The heat efficiency of the drying system is evaluated and compared with a conventional drying system using air dehumidified by condensation. The evaluation concerns the effect of stage number, inlet dryer temperatures $10-50^{\circ} \mathrm{C}$ and inlet ambient air $10-25^{\circ} \mathrm{C}$. Results show that the performance of the multi-stage adsorption dryers increases with the number of stages and a three stage system is economically most promising. For varying ambient air conditions, zeolite as adsorbent is the most favourable.
\end{abstract}

\section{Background}

Low temperature drying in the temperature range $10-50^{\circ} \mathrm{C}$ is favorable to limit product deterioration such as browning, shrinkage, structure deformation, the loss of valuable organic content is inhibited and product quality is retained [1]. However, the processes are expensive, need long operational time, and are complex if applied under vacuum and/or refrigerating conditions. Moreover, heat efficiency is below that for high temperature drying.

Condensation of water from air by cooling the air below dew point temperature is a common approach for air dehumidification in low temperature dryers. Air dehumidification by adsorbents as zeolites and pillared clay can also be applied to reduce the water content in air, and improves dryer efficiency [2]. A simulation study of single and multi-stage zeolite drying for the temperature range $50-90^{\circ} \mathrm{C}$ showed that a heat efficiency of $75-90 \%$ can be achieved, and in special configurations for heat recovery the efficiency may go up to $120 \%[3,4]$. 
This paper presents the potential of low temperature dryers using zeolite and alumina pillared clay for air dehumidification compared to condensation dryers.

\section{Methodology}

The heat efficiency is evaluated for dryers operating in the temperature range 10$50^{\circ} \mathrm{C}$ and using ambient air conditions throughout the seasons (see table 1). Air is dehumidified by zeolite, alumina pillared clay and by a condensation dryer. The material properties, assumptions and steady state mass and heat balances has been given in previous work of Djaeni et al [3] and Yamanaka et al [5].

Table 1: Average ambient Dutch air conditions in different seasons

\begin{tabular}{lcccc}
\hline Temperature /Relative Humidity & $10^{\circ} \mathrm{C} / 80 \%$ & $15^{\circ} \mathrm{C} / 70 \%$ & $20^{\circ} \mathrm{C} / 60 \%$ & $25^{\circ} \mathrm{C} / 50 \%$ \\
\hline Humidity kg vapor/kg dry air & 0.006 & 0.007 & 0.009 & 0.01 \\
\hline
\end{tabular}

\subsection{Process Description}

\subsubsection{Conventional condensation dryer}

Figure 1 presents the configuration of the condensation dryer. Ambient air is cooled below its dew point and water condenses in the condenser. The cooled air from the condenser is used either for cooling the air in chiller (if the ambient air temperature is above the exhaust air from dryer) or for cooling the recycle air from the dryer (if the ambient air temperature is below the exhaust air from dryer). The dried air is then heated in the heater to the inlet dryer temperature conditions.

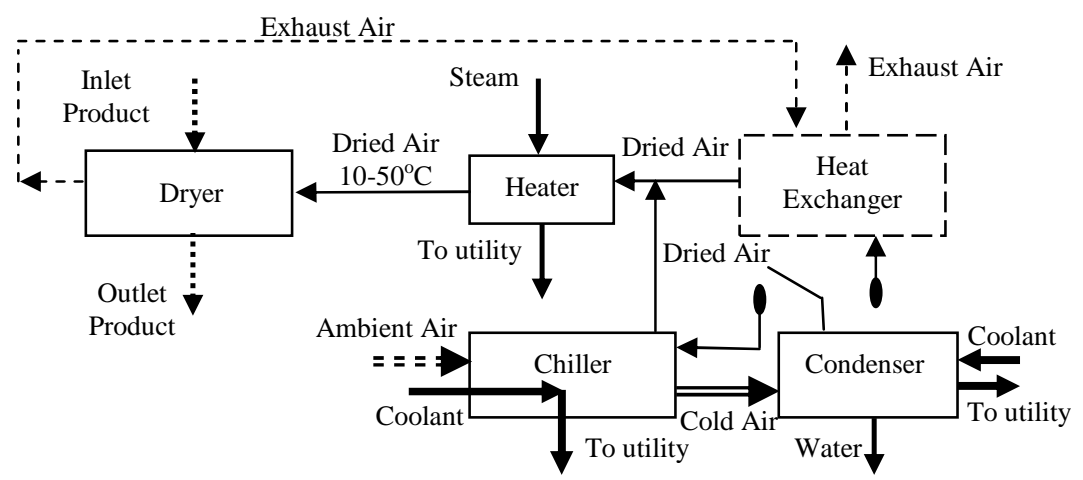

Figure 1: Low temperature condensation dryer 


\subsubsection{Multi-stage adsorbent dryer}

The counter current multi-stage dryer as illustrated in figure 2 is considered [4]. Ambient air is dehumidified in the first adsorber till $90 \%$ and $70 \%$ below the input value by using zeolite and alumina pillared clay respectively. In the adsorber the air temperature increases due to the release of the adsorption heat. Depending on the drying conditions, the dried air is cooled or heated in the conditioner before using in dryer. Meanwhile, saturated adsorbent is sent to the regenerator to release water in the temperature range $120-300^{\circ} \mathrm{C}$. The desorption heat is $3200 \mathrm{~kJ} / \mathrm{kg}$ water for zeolite and $2600 \mathrm{~kJ} / \mathrm{kg}$ water for alumina pillared clay $[3,4,5]$. For the next stage, air exiting dryer and regenerator is re-processed for use in the next stage. The product comes from adjacent dryer up stream and is dried further in the current stage.

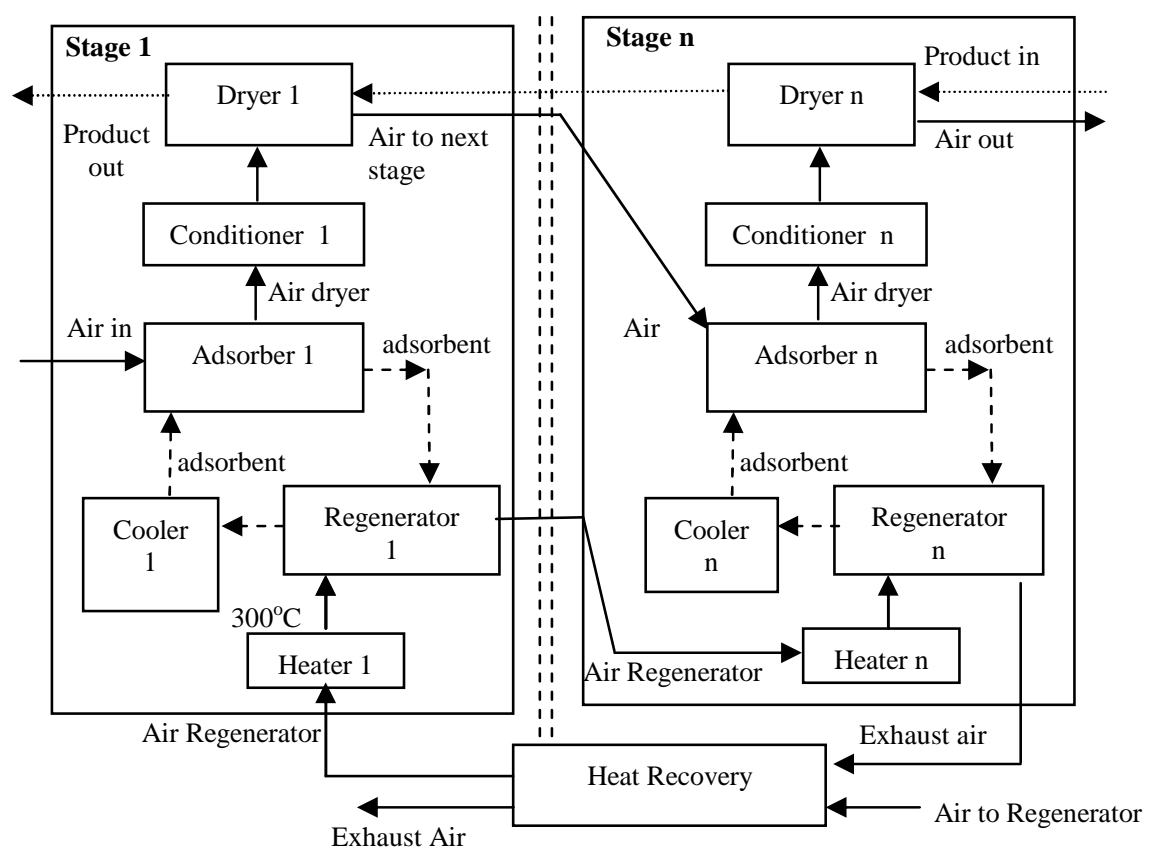

Figure 2: Multi-stage counter-current low temperature adsorbent dryer

\subsection{Heat recovery}

The heat recovery unit used for both the condensation and zeolite dryers $[3,4,7]$ is based on the pinch concept from Linnhoff [6]. In this work, a basic pinch procedure is used to recover heat from the exhaust air leaving the last stage 
regenerator and the adsorbent flow exiting each regenerator. The heat is used to heat up air before entering heater 1 , and the air leaving the first stage of adsorber if its temperature is below the design condition. The heat transfer estimation used minimum temperature difference $10^{\circ} \mathrm{C}$.

\subsection{Performance evaluation}

The overall efficiency is given as [3,4]:

$$
\begin{aligned}
& \eta=\frac{Q_{\text {evap }}}{Q_{\text {req }}} 100 \% \\
& Q_{\text {evap }}=F_{p}\left(X_{p, \text { in }}-X_{p, \text { out }}\right) \Delta H_{v} \\
& Q_{\text {req }}=\sum_{i=0}^{i=n}\left(Q_{h e}\right)_{i}-Q_{\text {rec }}
\end{aligned}
$$

where $F_{p}$ is the mass flow of dry product $(\mathrm{kg} / \mathrm{hr}), X_{p, \text { in }}$ and $X_{p, \text { out }}$ are the product water content towards and from the system ( $\mathrm{kg}$ water $/ \mathrm{kg}$ dry product), $\Delta H_{v}$ is the latent heat of water evaporation $(\mathrm{kJ} / \mathrm{kg}), Q_{\text {evap }}, Q_{\text {rec }}, Q_{\text {req }}, Q_{\text {he }}$ are total heat for water evaporation, heat recovered, heat consumed, and the heat used in heat exchangers $(\mathrm{kJ} / \mathrm{hr}), \eta$ is the heat efficiency (\%), and subscripts of $i$ and $n$ refer to the stage number and the total number of stages.

\section{Result and discussion}

\subsection{Effect of temperature and number of stages on efficiency}

Figure 3 shows that the heat efficiency of the adsorbent dryer increases with increasing temperature and stage number. For temperatures below $40^{\circ} \mathrm{C}$, the stage number has a significant effect on the heat efficiency. Above three stages improvement is marginal and therefore a three stage dryer is economically most promising for every temperature level.

Alumina pillared clay has a limited capacity to adsorb water from air. As a result the heat efficiency of alumina pillared clay is $5-10 \%$ below that of the dryer using zeolite. Moreover, the dryer using alumina pillared clay can not operate below $20^{\circ} \mathrm{C}$.

The system recovers hot streams with higher temperature only. Therefore, the heat in the air leaving adsorber can not be recovered since all cold streams need higher temperature levels. Adsorption heat obtained in the adsorbers is in the most cases not used. 


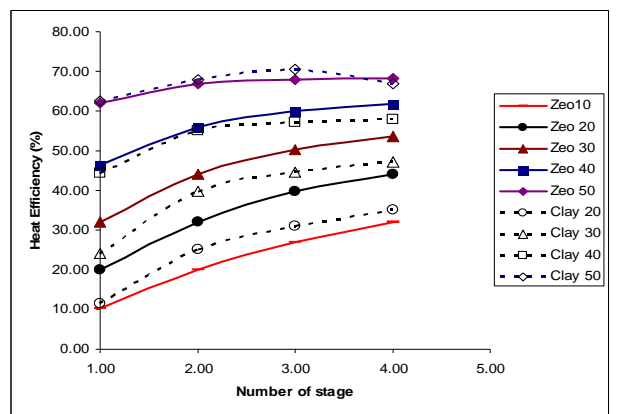

Figure 3: Heat efficiency for the multi-stage dryers as a function of the number of stages and drying temperature

\subsection{Varying ambient conditions}

Figure 4 presents the heat efficiency of the condensation dryer and the three stage adsorbent dryers. The results show that for the lower ambient temperatures, the heat efficiency of the adsorbent dryers surmounts that of the condensation dryer. This positive effect is result of the lower amount of heat released in the adsorber. The lower temperatures and the humidity values (see table 1) make that less water is adsorbed and as a result the dried air from the adsorber requires not much additional heat. In addition, the load of regenerator decreases as less water has to be removed. Thus, two advantages are obtained: less heat for zeolite regeneration and more heat can be recovered.

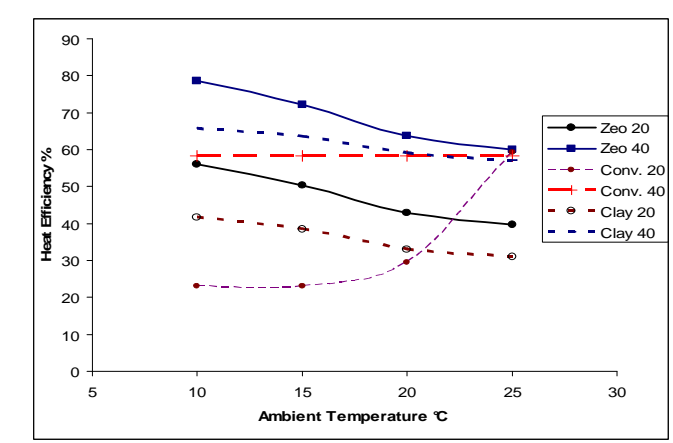

Figure 4: The effect of ambient temperature on heat efficiency

In contrast, for inlet dryer temperature below $40^{\circ} \mathrm{C}$, the heat efficiency of the condensation dryer decreases as well as the decrease of inlet ambient temperature. Ambient air as hot stream source has a lower temperature level which limits the heat recovery potential. Whereas, at higher inlet dryer 
temperatures, the system uses exhaust air from dryer as hot stream source that has constant temperature level. Hence, the efficiency can be kept at constant value.

\section{Conclusion}

The heat efficiency of low temperature dryers using air dehumidified by zeolite is more profitable compared to dryers using alumina pillared clay at dryer temperatures below $40^{\circ} \mathrm{C}$. At higher temperatures, the performance is similar. Compared to dryers with a condensation system for air dehumidification, dryers using adsorbents are superior at ambient temperature below $20^{\circ} \mathrm{C}$. The difference in heat efficiency is the highest for low ambient temperatures. Even for ambient temperatures of $10^{\circ} \mathrm{C}$, the efficiency of adsorbent dryers is $20-40 \%$ higher than that of condensation dryers.

\section{References}

1. Ratti C. Hot air and freeze-drying of high-value foods: a review. Journal of Food Engineering 2001, 49, 311-319

2. Revilla, G.O.; Velázquez, T.G.; Cortés, S.L.; Cárdenas, S.A. Immersion drying of wheat using Al-PILC, zeolite, clay, and sand as particulate media. Drying Technology 2006, 24, 1033-1038

3. Djaeni, M.; Bartels, P.; Sanders, J.; Straten, G. van; Boxtel, A.J.B. van. Process integration for food drying with air dehumidified by zeolites. Accepted in Drying Technology 2007, 25 (1)

4. Djaeni, M.; Bartels, P.; Sanders, J.; Straten, G. van; Boxtel, A.J.B. van. The improvement of zeolite dryer through development of multistage dryer combined by compressor utility. Submitted to Drying Technology November 2006

5. Yamanaka, S.; Malla, P.B.; Komarneni, S. Water adsorption properties of alumina pillared clay. Journal of Colloid and Interface Science 1990, 134 (1), 51-58

6. Linnhoff, B. User Guide of Process Integration for The Efficient Use of Energy. Institution of Chemical Engineers, UK, 1994

7. Kemp, I.C. Reducing dryer energy use by process integration and pinch analysis. Drying Technology 2005, 23, 2089-2104 